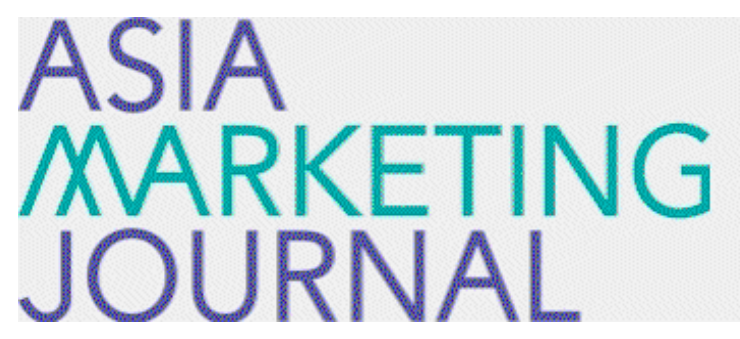

ASIA MARKETING JOURNAL

Volume 5 | Issue 1

Article 4

3-25-2003

\title{
시장지향적 문화, 마케팅전략, 성과간의 관계에 관한 연구
}

상욱 김

성호 이

서일 채

최

Follow this and additional works at: https://amj.kma.re.kr/journal

Part of the Marketing Commons

\section{Recommended Citation}

깁, 상욱; 이, 성호; 채, 서일; and 최 (2003) "시장지향적 문화, 마케팅전략, 성과간의 관계에 관한 연 구," Asia Marketing Journal: Vol. 5 : Iss. 1 , Article 4.

Available at: https://doi.org/10.53728/2765-6500.1102

This Article is brought to you for free and open access by Asia Marketing Journal. It has been accepted for inclusion in Asia Marketing Journal by an authorized editor of Asia Marketing Journal. 


\title{
시장지향적 문화, 마케팅전략, 성과간의 관계에 관한 연구*
}

\section{The Relationships Among Market-Oriented Culture, Marketing Strategy Making, and Firm Performance}

\author{
김상욱 (한신대학교 e-business학과 조교수) \\ drsukim@hanshin.ac.kr \\ 이성호(서울시립대확교 경영학부 부교수) \\ shleeQuos.ac.kr \\ 채서일(고려대학교 경영학과 교수) \\ schaiyekorea.ac.kr \\ 최수호(고려대학교 경영학 박사) \\ cshdrenaver.com
}

기업성과에 대한 마케팅 공헌에 관한 기존 연구의 노력은 시장지향성과 마케팅전략의 영역에서 많이 수행되어 왔다. 최근 들어 두 영역의 개념들을 통합하여 성과에 미치는 마케팅의 영향력을 살펴보려는 노력이 등장하고 있다. 본 연구는 이러한 통합연구의 흐름에 일조할 목적으로, 시장지향적 문화와 마케팅전략과정(Marketing Strategy Making Process)을 기업의 마케팅역량을 구성하는 차원으로 제기하고 관련문헌 고찰에 기반하여 시장지향적 문화가 마케팅전략과정올 동인(動因)하는 관계를 설정하고, 기업관리자률 대상으로 한 실증조사를 통하여 이러한 관계를 중명하였다. 구체적으로 시장지향적 문화는 성과에 직접적으로 영향을 미침과 동시에 마케팅전략과정을 통하여 간접적인 영향도 미치고 있음을 밝혔다. 즉 성과를 제고시키기 위하여 기업은 시장지향적 문화의 토대 위에서 충실한 마케팅전략과정을 이행해야 할 것이다.

* 논문접수 : 02,10 계재확정 : 03,03

본 연구는 2001 년 고려대학교 기업경영연구원 학술연구비의 지원에 의한 것임.

시장지항적 운화, 마케팅전략, 성과간의 관계에 관한 연구 67 


\section{1. 서 론}

기업이 마케팅을 얼마나 잘 이해하고 실천하는가와 이것이 기업성과에 어떤 영향을 미치는가에 대해서는 다양한 주제 하에서 많은 연구가 이루어졌는데, 이 연구들은 대부분 문화와 전략 차원에서 마케팅의 역할을 다룬 것으로 요약될 수 있다(Hooley et al,, 1999; Mooreman \& Rust, 1999; Webster, C., 1993, 1995; Webster, F. E., 1988, 1994).

문화 차원의 마케팅은 고객의 중요성에 대한 가치관과 신넘의 체계가 조직에 반영되어 마케팅 활동으로 연계되는 정도를 의미한다(Webster, 1995). 문화로서의 마케팅에 대한 연구들은 마케팅개념의 실천과 성과 사이의 관계를 규명해주고 있다. 즉 문화로서의 마케팅은 직접 성과를 설명하기 보다 학습지향성(Baker \& Sinkula, 1999; Sinkula, 1994; Slater \& Narver, 1995)이나 마케팅전략(Morgan \& Strong, 1998; Slater \& Narver, 1993 , 1995; Ruekert, 1992)과의 상호 작용 또는 매개 과정을 통해 성과와 연관될 수 있을 것이다.

전략으로서의 마케팅은 선택된 사업영역에서 시장 세분화·표적화·포지셔닝(STP) 전략을 중심으로 기업의 경쟁방식을 결정하는 것을 의미한다(Webster, 1995). 전략으로서의 마케텅 수준 역시 성과에 긍정적인 영향을 주는 것으로 밝혀졌지만(Menon et al., 1999; Noble \& Mokwa, 1999), 문화적인 요소라는 선행변수의 영향을 받는 것으로 알려져 있다(Bigne et al., 2000; Morgan \& Strong, 1998; Ruekert, 1992).

즉 기존의 많은 연구들은 문화나 전략으로서의 마케팅이 성과에 미치는 개별적인 영향을 살펴보았으며, 문화와 전략차원의 마케팀이 어떻게 동시에 성과에 영향을 미치는가를 다룬 통합적인 관점의 연구는 상대적으로 부족한 편이다. 한편 통합적 관점올 가진 소수의 연구들(Kotler, 1977; Hooley et al., 1999; Morgan \& Strong, 1998; Ruekert, 1992; Slater \& Narver, 1996)은 문화와 전략 차원의 마케팅에 대한 개념 정립, 구성 항목들간의 관계설정, 측정 둥에 있어 문제점을 가지고 있다. 따라서 본 연구는 이러한 문제점을 해결하면서 문화적 차원과 전략적 차원의 마케팅이 어떻게 기업성과에 영향올 미치는지를 규명하였다. 이를 위하여 본 연구는 먼저 문화로서의 마케팅과 전략으로서의 마케팅에 대한 개념을 충실하게 정립하고자 하였다. 조직문화와 기업전략에 대한 연구를 고찰하면서 기존 연구에 비하여 마케팅 고유의 특성을 더 충실하게 반영하였다. 다음에서는 관련된 문헌을 고찰하고 이를 바탕으로 본 연구가 설정한 가설을 제시하였다. 그런 후 연구방법과 분석결과를 제시하였으며 끝으로 연구결과의 의의, 한계점과 향후 연구방향을 논의하였다.

\section{2. 이론적 고찰 및 연구가설}

\section{1 문화로서의 마케팅(Marketing as Culture)}

\subsection{1 시장지향적 문화}


조직문화의 개념에 바탕을 둔 마케팅의 대표적인 연구흐름으로는 시장지향성에 관한 연구들이 있다(예 : Harris, 1998; Kohli \& Jaworski, 1990; Narver \& Slater, 1990; Webster, 1993, 1995). 시장지향적인 문화는 고객 지향, 경쟁자 지향, 부서간 협력으로 구성되며, 고객에게 더 높은 가치를 창조하기 위해 필요한 행동을 가장 효과 효율적으로 유발함으로써 우월한 사업성과를 지속적으로 제공해 주는 조직문화로 정의된다(Narver \& Slater, 1990). 즉 시장지향적인 문화는 마케팅조직뿐만 아니라 전반적인 조직의 운영지침으로서 고객의 중요성을 강조하며 모든 기업구성원이 이러한 가치관과 신념체계를 가지고 자기 임무를 수행하라는 마케팅개념(marketing concept)을 보다 실천적인 방향으로 정립하였다(Harris, 1998; Hooley et al., 1999; Webster, 1993), 이에 따라 시장지향성 개념의 정립과 측정, 그리고 시장지향성이 성과에 미치는 영향에 관한 많은 연구들이 등장하였다(예 : Deshpande \& Farley, 1998; Han et al., 1998; Lafferty \& Hult, 2001; Narver \& Slater, 1990, 1998; Slater \& Narver, 1994; 김재욱-전광호·이성근, 2001 ; 노전표, 1998; 이용기 · 유동근 · 이하식, 1996).

이러한 많은 기존 연구는 시장지향성과 성과와의 유의한 관계를 보여주었다. 그러나 이러한 연구들이 시장지향성을 조작적으로 정의하는 과정에서 개념타당성에 관한 문제를 내포하고 있다는 점이 지적되기 시작하였다. 예를 들어 Homburg와 Pflesser (2000)는 기존 연구들(예 : Narver \& Slater, 1990)이 시장지향성을 문화로 정의하였지만 측정에서는 행동척도를 사용함으로써 시장지향적인 문화가 갖는 좀 더 근원적인 요소들이 반영되고 있지 못함(under-represented)을 지적하고, 문화의 개념과 구성요소를 좀 더 충실하게 반영한 시장지향성 측정척도를 제시하였다.

이들은 마케팅과 조직분야의 연구를 바탕으로 문화는 어떤 유형의 행동을 유발하게 해주는 가치관(values), 규범(norms), 인위적인 장치(artifacts) 둥의 체계라고 정의하였다(Deshpande \& Webster, 1989; Schein, 1992). 여기서 가치관이란 행동양태의 선택에 영향올 주는 바람직함에 대한 개넘을 의미하며, 규범은 가치관보다는 구체적인 행동에 영향을 주는 행동에 대한 기대를 뜻하고, 인위적인 장치는 화제(話題), 시설, 의식, 언어 행태 둥 조직이 인위적으로 만든 상징적인 요소들올 말한다. 이러한 정의를 종합하여 Homburg와 Pflesser (2000)는 시장지향적인 조직문화를 (1) 시장지향적 가치관, (2) 시장지향적 규범, (3) 시장지향성에 관련된 인위적인 장치, (4) 시장지향적 행동이라는 4개 요소의 계충적인 구조로 개념화 하였으며, 문화의 구성요소 중 가장 하위개념인 행동이 성과에 영향을 미침을 밝혔다(<그림 $1>$ 참조).

<그림 1> Homburg와 Pflesser (2000)의 시장지향적 조직문화 개넘도

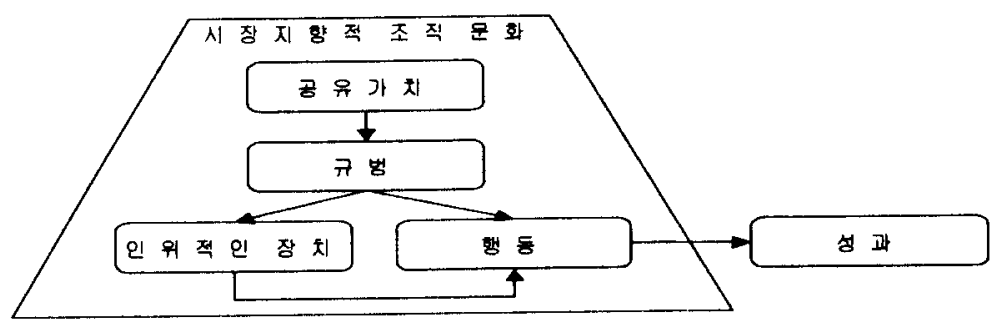

그러나 문화 구성요소들간의 관계를 계충적으로 설정한 것은 너무 한정적이라 할 수 있다. 
Schein (1992)과 달리, Hatch (1993)는 문화 구성요소들이 수직적인 계충 관계에 있기 보다 각 요소들이 명료화, 가시화, 상징화, 해석 과정을 통해 상호 연관되어 있는 역동적인 구조를 가지고 있다고 주장하고 있다. 즉 Hatch (1993)의 모형은 Schein (1992)의 모형보다 시장지향적 문화 구성요소들간의 관계를 보다 더 역동적으로 반영할 수 있다는 장점을 가지고 있다. 따라서 본 연구는 문화로서의 마케팅을 구성하는 요소간의 역동적인 관계를 상정하여 시장지향적 문화를 개념화 하였다(<그림 2> 참조).

<그림 2> Hatch (1993)의 조직문화에 기초한 시장지향적 문화의 개념도

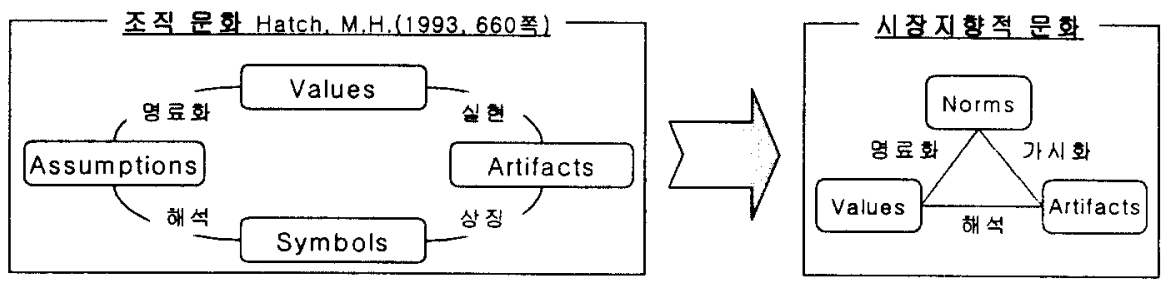

\subsection{2 시장지향적 문화와 성과}

시장지향적 문화는 고객에게 더 높은 가치를 창조하기 위해 필요한 행동을 가장 효과·효율적으로 유발함으로써 우월한 사업성과를 지속적으로 제공해 주는 조직문화이다 (Narver \& Slater, 1990). 여기서 고객이 지각하는 가치는 제품이나 서비스로부터 기대한 효용과 고객이 지각하는 홍 구입·사용비용의 차이로 정의할 수 있다(Zeithaml, 1988; Zeithaml et a1,, 1990). 그러므로 시장지향적인 기업은 고객에게 더 많은 부가가치를 제공하고 동시에 고객의 비용을 절감시키기 위한 제반 조치를 강구할 것이다. 따라서 시장지향성은 성과에 긍정적인 영향을 줄 것이라는 가설을 수립할 수 있다. 기존의 많은 연구들 또한 시장지향성이 성과에 유의한 영향을 준다는 점을 밝힌 바 있다. 그러나 이러한 기존 연구들과 달리 본 연구는 시장지향적 문화를 행동이 아닌 문화의 구성요소로 개념화·조작화하고 있으며, 문화 구성요소들의 관계를 계충적인 구조가 아닌, 역동적인 관계로 보고 있다.

가설 1 : 시장지향적 문화는 성과에 긍정적인 영향을 줄 것이다.

\section{2 전략으로서의 마케팅(Marketing as Strategy)}

\subsection{1 마케팅전략연구의 분류(typology)}

기업성과에 영향을 미치는 요인에 관한 연구에 있어 마케팅전략의 영향력에 관한 연구의 비중은, 매우 높다(Bonoma, 1984; Bonoma \& Crittenden, 1988; Cespedes, 1991; Cespedes \& Piercy, 1996; Gummesson, 1998; Hamel \& Prahalad, 1994; Menon et al., 1999; Noble \& Mokwa, 1999; Piercy, 1998). 마케팅전략의 내용과 과정에 관한 연구들은 크게 전략 수립 문제와 과정에 초점을 맞춘 합리적 기힉론 학파(the rational planning school)와 전략 실행 문제와 과정에 집중한 중분론 학파(the incremental school)의 연구로 나누어 볼 수 있다(Barney, 1997; Grant, 1995; Nutt, 1993; Speed, 1993). 그러나 이러한 양분론적 
접근이 전략연구를 정체시켰다는 비판과 더불어 최근에는 전략의 수립과 실행과정을 통합한 관점에서 전략의 효과를 고찰한 연구가 둥장하고 있다(Menon et al., 1999; Piercy, 1998). 본 연구 또한 통합적인 관점에서 전략의 수립과 실행과정상의 충실함 정도로 기업의 전략수준을 정의하고 측정하였다.

한편 연구방법을 기준으로 할 때, 마케팅전략에 관한 연구는 묘사적인 접근(narrative approach), 분류적인 접근(classificatory approach), 그리고 비교적인 접근(comparative approach)으로 나누어 볼 수 있다(Chaffee, 1985; Morgan \& Strong, 1998). 묘사적인 접근은 주로 사례연구에서 활용되며, 정성적인 방법론을 활용하여 전략의 특성을 기술하는 데 주안점을 두고 있다. 이러한 정성적인 접근법은 주로 조직연구분야에서 많이 활용되고 있으며, 이론의 검중보다는 이론 수립의 초석을 제공하는 것으로 평가할 수 있다. 분류적인 접근은 일정한 기준에 의해 전략유형을 분류하는 것을 말한다(Miles \& Snow, 1978; 김혼·채서일, 1996 ; 전인수·김주환, 2001). 가장 대표적인 연구로는 Miles와 Snow (1978)의 전략유형에 관한 연구를 들 수 있다. 분류적인 접근은 이론적인 토대나 전략적인 시사점을 도출하는 면에서 상당한 기여가 인정되고 있다. 그러나 이 접근법은 톡정상황에서 가장 유리한 전략유형을 규명함으로써 전략유형 간의 상대적인 비교는 가능하나, 동일 전략 유형에 속하는 기업들간의 비교와 그들의 전략적인 이슈를 해결하여 주지 못한다. 비교적인 접근은 분류적인 접근이 갖는 한계률 극복하여 준다. 이 접근법은 전략 핵심요소의 규명과 측정에 주안점을 두고 있기 때문에 이 핵심요소들을 기준으로 전략유형에 상관없이 기업간 마케팅전략의 수평적인 비교를 가능하게 해준다(Speed, 1993). 따라서 본 연구도 이러한 비교적인 접근을 채택하여 기업 마케팅전략의 수준에 따른 성과의 차이를 분석하고자 한다.

즉 본 연구는 마케팅전략의 수립과 실행을 통합한 관점에서, 비교적인 접근을 통해, 연구한 Menon 등(1999)의 마케텅전략과정(Marketing Strategy Making, 이하 MSM)과 동일한 접근을 채택하였다. 마케팅전략과정은 기업이 최선의 마케팅전략을 선택했는지 보다 마케팅 전략을 수립하고 실행함에 있어 얼마나 원칙에 충실했느냐를 측정하는 개념이다 ${ }^{1}$.

\subsection{2 마케텅전략과정(MSM)}

Menon 둥은 마케팅전략의 수립과 실행을 통합한 개념인 마케팅전략과정을 "마케팅 계획의 수립과 실행에 관련된 활동, 과정, 관례들로 구성된 복잡한 집합(a complex set of activities, processes, and routines involved in the design and execution of marketing plans; Menon et al., 1999)" 으로 정의하였다. 구체적으로 이들은 MSM을 상황분석 (situation analysis), 포괄성(comprehensiveness), 마케팅자산과 역량의 강조(emphas is on marketing assets and capabilities), 기능간 통합(cross-functional integration), 의사소통품질(communication quality), 합의도출에 대한 몰입(consensus commitment), 자원 몰입(resource commitment)의 요소들로 구성하고, 선행연구결과와 실무진과의 면접결과에 근거해 MSM의 수준에 따라 성과가 결정되는 관계를 상정하였다.

상황분석은 마케팅전략 영역에서 조직의 강-약점, 기희-위협요인(SWOT)을 합리적이고 체계적으로 고려하는 것을 의미한다(Bourgeois \& Eisenhardt, 1988; Kohli \& Jaworski,

1 이외에도 중요한 전략연구의 분류 체계로 내용(content)중심의 전략과 과정(process)중심의 전략이 있다. 이 체계로 볼 때 본 연구는 어느 한 쪽으로 분류되기는 어렵지만 상대적으로 과정중심의 전략에 가깝다고 할 수 있으며(Mintzberg \& Quinn, 1996; 장세진, 2002), 이 점을 지적한 심사자에 감사 드린다. 
1990). 상항분석은 환경의 변화가 시사하는 기회와 위협요인을 규명하고 이해하는 과정으로 그 기업이 환경과 전략간에 있어 최상의 적합도를 갖도록 해줌으로써 성과에 긍정적인 영향을 미친다(Bourgeois \& Eisenhardt, 1988; Capon et al., 1994; Eisenhardt, 1989; Grant, 1995).

포괄성이란 전략을 선택할 때 체계적으로 전략대안들을 도출하고 심도 긿은 분석을 실시하는 것올 말한다(Eisenhardt, 1989; Fredrickson, 1983). 다양한 전략대안을 도출하는 전략의 포괄성은 복수대안의 평가를 통해 각 대안의 실행가능성이 평가되게 함으로써 최적대안의 선택 가능성올 높여 준다(Schweiger et al., 1986). 이러한 논거에 의하여 상정된 전략의 포괄성과 성과간의 긍정적인 관계는 실증연구를 통해서도 입증되었다(McKee et al., 1990).

마케팅자산과 역량에 대한 강조는 마케팅전략의 토대를 이루는 마케팅 관련 핵심업무 프로세스, 자원, 기법에 대한 지속적인 활용을 의미한다(Bharadwaj et al., 1993; Day, 1994). 마케팅자산이란 규모와 범위의 설비투자, 브랜드자산, 유톻망 우위와 같은 마케팅이 투자하여 활용할 수 있는 자원을 뜻하며, 역량(capabilities)이란 가격전략, 고객서비스, 혁신, 제품개발 둥과 같은 자산의 활용 능력을 의미한다(Day, 1994). 마케팅자산과 역량에 대한 강조, 특히 다양한 종류의 역량에 대한 강조는 우월한 성과에 긍정적으로 작용할 것으로 제안되었다(Bharadwaj et al., 1993; Day, 1994).

기능. 부서간 통합 정도는 MSM팁이 얼마나 전체 조직을 대표하고 있으며, 얼마나 잘 조직화·조정되고 있는가를 나타낸다(Ayers et al., 1997; Miller, 1987). 전략의 성공적인 실행을 위해서는 다양한 기능들로 구성된 이른바 전략실행팀의 기능 통합이 펄요하며, 이들 팀과 전체 조직간의 기능적 - 정치적 유대가 필요하다(Menon et al., 1999). 이러한 연구 결과들과 실무진들의 견해를 종합해볼 때 기능- 부서간 통합 정도는 시장성과에 긍정적인 영향을 줄 것으로 상정할 수 있다(Ayers et al., 1997; Olson et al., 1995).

의사소통품질은 전략수립과정에서의 공식적·비공식적 의사소통의 본질과 정도를 의미한다(Bonoma, 1985; Miller, 1987). 양질의 의사소통은 전략이 캐도에서 이탈되는 것을 방지하고 전략실행의 조정력을 제고함으로써 전략 성패의 열쇠 역할을 한다. 의사소통의 품질이 시장성과에 긍정적인 영향을 준다는 점은 여러 실증 연구에서 입중되었다(Kohli \& Jaworski, 1990; Narver \& Slater, 1990).

합의도출에 대한 몰입은 선택된 전략에 대하여 전략팀 구성원들이 동의하고 지원하는 정도를 의미한다(Wooldridge \& Floyd, 1989). 합의와 의견일치는 의사결정과정에 대한 공통의 이해를 통해 의사결정에 대한 불확실성을 감소시키고 주의를 집중시킬 수 있으며 내부의 정치적 역학관계나 갈등 해소에 소요되는 시간을 줄여줌으로써 전략 실행에 내실을 기할 수 있게 해준다(Iaquinto \& Fredrickson, 1997). 즉 합의도출에 대한 몰입은 전략에 대한 각 개인의 노력의지, 전략 목표에 대한 일체감과 연관되므로 시장성과와 긍정적인 관계를 갖는다고 상정할 수 있다.

자원몰입은 마케팅전략을 추구하는 데에 적정 수준의 인력, 시간, 자금을 할당하는 것을 말한다(Ramanujan et al., 1986). 전략은 실질적인 자원의 투입을 통하여 실행되는데, 자금이 가장 명확한 자원으로 보이지만, 시간이나 인적 자원도 중요하다. 사업성과에 대한 자원몰입도의 영향에 대해서는 예외가 있기는 하지만(Ramanujan et al., 1986), 대체로 긍정적인 영향을 상정하고 있다(Day, 1983).

이상에서 고찰한 바와 같이 마케팅전략과정(MSM)을 구성하는 제 요소들은 각각 성과에 
긍정적인 영향을 줄 수 있을 것으로 예상할 수 있으며, 실중적인 연구에서도 이러한 관계는 입증되었다(Menon et al., 1999).

\section{2 .3 마케팅전략과정(MSM) 개념의 개선}

Menon 등(1999)은 기업전략과정의 일반적인 요소(Boyd \& Reuning-E1liott, 1998; Hart \& Banbury, 1994; Wernerfelt, 1984)를 중심으로 마케팅전략과정올 정의 측정하였으며, 전략 수립 시 얼마나 다양한 마케팅자산과 역량을 강조하는가를 고려함으로써 마케팅전략의 차별적인 요소를 반영하였다. 그러나 이들이 사용한 마케팅자산과 역량에 관한 항목들(1) 경쟁사 대비 낮은 가격 구사, (2) 신제품 개발, (3) 폭 넓은 제품라인의 확보, (4) 고객서비스 역량의 확충, (5) 브랜드 이미지 구축, (6) 기존 제품의 개선, (1) 상품의 품질우위 확보, (8) 유통망에 대한 강력한 통제력 확보, (9) 특정 지역에 대한 시장 집중, (10) 업계 평균 이상의 광고-판촉비 지출, (11) 고가 세분시장용 상품 출시, (12) 저가 세분시장용 상품 출시, (13) 마케팅 기법상의 혁신)이 마케팅전략의 특성을 얼마나 잘 반영하고 있는가라는 점에서는 몇 가지 의문을 제기할 수 있다.

먼저 마케팅자산과 역량에 관한 항목들이 전략적 일관성(Capon et al., 1994; Kotler. 1997; Venkatraman, 1989)을 고려하고 있는가에 관한 의문이다. 이 항목들은 마케팅전략 수립 시 고가 세분시장과 저가 세분시장에 대한 집중을 동시에 측정하고 있다. 그러나 이러한 접근은 전략적 일관성의 관점에서 볼 때 문제가 된다. 이러한 접근은 두 세분시장 모두 목표시장으로서 충분한 가치가 있음이 입중되고 이 시장에 동시에 접근할 수 있는 기회와 자원이 보장되는 상황에서만 적합한 전략이라 할 수 있다. 따라서 모든 상황에서 적용될 수 있는 마케팅자산과 역량 항목들을 정의 ㅊㅊㄱ정하는 것은 무리라고 평가할 수 있다.

두 번째로 마케팅자산과 역량에 대한 기본 가정에 관한 의문이다. 경쟁사대비 낮은 가격의 구사, 유통망에 대한 통제력 확보 등의 경우 마케팅자산과 역량을 지나치게 좁게 정의하는 위험을 안고 있다. 예를 들어 가격전략의 경우 가격은 품질의 지표로 활용되는 면이 있기 때문에 경쟁사보다 낮은 가격을 구사하는 것이 반드시 유리하지는 않올 것이다(Monroe \& Krishnan, 1985). 즉 경쟁사 대비 낮은 가격을 토대로 한 경쟁우위의 확보만이 마케팅역량의 척도가 될 수는 없다. 마찬가지로 유통망의 경우도 통제보다는 신뢰와 몰입을 통한 장기적인 관계의 구축이 더욱 훌륭한 경쟁우위의 원천이 될 수 있다(Dwyer \& Oh, 1988; Morgan \& Hunt, 1994).

세 번째는 마케팅자원 활용의 효율성을 얼마나 고려하고 있는지에 대한 의문이다. Menon 둥 (1999)은 경쟁사대비 높은 광고 - 판촉비용의 지출을 강조하였다. 그러나 장기적 마케팅 활동이 창출하는 마케팅자산의 개념은 효과성은 물론 효율성(예 : 높은 자산의 브랜드는 상대적으로 적은 마케팅 비용을 유도함)을 전제하고 있다는 점에서 경쟁사대비 높은 광고·판촉비용의 지출을 강조하는 부분은 문제이다(Narver \& Slater, 1990). 광고. 판촉비의 효과에 관한 연구들은 광고·판촉비의 매출함수 규명을 통하여 마케팅 자원활용의 효율화가 가능함을 제시하고 있다(박세훈, 1994). 따라서 단순히 경쟁사보다 많은 광고·판촉비를 사용한다는 것만으로는 기업의 마케팅자산과 역량의 수준을 촉정하기는 어럽다

이밖에도 Menon 둥(1999)은 기업전략과 마케팅전략 모두에서 목표지향적인 행동의 유발과 관리수단으로 활용되고 있는 통제활동을 측정하지 않고 있다는 문제점을 내포하고 있다 (Becker \& Homburg, 1999; Boyd \& Reuning-Elliott, 1998; Kotler, 1977, 1997). 
이러한 문제점들을 감안할 때 마케팅전략과정수준의 측정을 위해서는 마케팅전략의 고유한 특성을 반영하는 개선 노력이 필요하다. 먼저 본 연구는 Hooley 등(1999)과 Kotler (1977, 1997)에 기반하여 마케팅전략에서 구체적인 전략의 선택기준 역할을 하는 세분시장 마케텅전략원칙(STP)과 그에 따른 마케팅실행에 해당하는 4P 믹스의 원칙을 반영해 주어야 함을, 그리고 목표지향적 행동을 관리해주는 마케팅통제활동을 포함시켜야 함을 제안한다. 이러한 개선 방향은 서로 상충되는 마케팅 운용방안 대신 마케팅전략의 수립과 실행과정이 마케텅철학에 충실한 정도를 촉정함으로써 기업별로 상이한 환경이나 마케팅전략유형과는 독립적으로 마케팅전략과정의 수준 비교를 가능하게 하는 것을 목표로 한다(<그림 3> 참조).

<그림 3> 본 연구의 마케팅전략과정 개념도

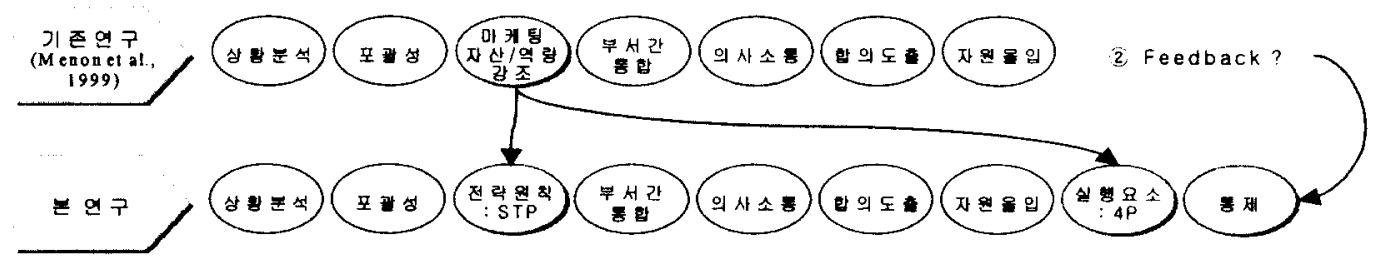

2.2.4 마케팅전략과정과 성과

본 연구는 마케팅전략과정을 상황분석, 포괄적인 대안도출-평가를 통한 전략선택, 세분화 마케팅전략원칙(STP), 기능- 부서간 통합, 의사소통, 합의도출, 자원몰입, 실행역량(4P 믹스), 통제로 구성된 일련의 프로세스로 정의하였다(Becker \& Homburg, 1998; Kot ler, 1997; Menon et al., 1999).

각 요소들은 내 - 외부 상황의 체계적인 고려를 통한 전략의 환경적합도 제고(Capon et al., 1994; Venkatraman, 1989), 효과적인 대안평가를 통한 최적 전략대안 선택확률의 제고(McKee et al., 1990), 시장현황에 대한 이해 확장을 통해 최적 전략 선택확률의 제고와 4P 믹스 실행방향의 제시(Kotler, 1997), 전략실행 시 오류의 조가 발견(01son et al., 1995), 전략실행 시 적웅력 및 조정력의 향상(Moorman \& Miner, 1998; Slater \& Narver, 1995), 의사결정에 대한 불확실성의 감소 및 주의집중의 유도(Iaquinto \& Fredrickson, 1997), 전략실행에 필요한 인력, 시간, 자금의 지원(Ramanujan et al., 1986), 목표고객의 욕구충족(Kotler, 1997), 목표지향적 행동 유도(Bartol \& Martin, 1998)를 통해 성과에 긍정적인 영향을 미치는 것으로 밝혀졌다. 즉 마케팅전략과정의 수준이 높다는 것은 내 · 외부 환경에 대한 체계적인 이해를 바탕으로 마케팅전략원칙에 의한 최적대안의 선택과 효과적·효율적인 실행이 가능함을 의미하는 것이다. 이에 따라 마케팅전략과정의 수준에 의하여 성과가 좌우될 수 있을 것이라고 예측한다.

가설 2 : 마케팅전략과정의 수준은 성과에 긍정적인 영향을 줄 것이다.

2.3 시장지향적 문화와 마케팅전략의 통합에 관한 연구

2.3.1 기존 연구 고찰 
문화와 전략으로서의 마케팅 요소들을 통합적인 틀에서 이해하려고 한 연구들 중(Hooley et al., 1999; Kotler, 1977; Morgan \& Strong, 1998; Ruekert, 1992; Slater \& Narver, 1996), 가장 대표적인 연구로는 Kotler (1977)의 마케팅 효과성(marketing effectiveness)에 관한 연구와 Hooley 등(1999)의 마케팅역량(marketing capabilities)에 대한 계충적 모델에 관한 연구를 들 수 있다. 마케팅 효과성에 관한 연구의 효시는 Kotler (1977)이다. 비록 명시적으로 정의하고 있지는 않지만 Kotler는 암묵적으로 마케팅 효과성을 "기업의 마케팅 이해와 실행 품질(whether an organization understands and practices marketing-and if so, how well; Kotler, 1977, p.67)" 로 정의하고 이를 측정할 수 있는 지표를 제시하였다. 마케팅 효과성에 대한 Kotler의 정의와 측정지표는 비록 정교한 측정항목 개발과정을 따르거나 폭 넓은 문헌연구에 기초하고 있지는 않지만, 문화와 전략차원의 마케팅 요소들을 통합적인 관점에서 고려하고 있다는 점에서 많은 연구자와 실무자들로부터 폭 넓은 지지를 받아 왔다(Appiah-Adu, 1999; Norburn et al., 1990; Sin \& Tse, 2000; Yoon \& Kim, 1999).

그러나 마케팅 효과성에 관한 연구는 높은 실무 적용 가능성을 가진 개념이라는 장점에도 불구하고 많은 한계점들을 가지고 있다. 우선 마케팅 효과성이 측정하고 있는 구성항목들이 이 개념을 제대로 측정하고 있는가에 관한 문제를 들 수 있다. Kotler는 총 15 개의 어의차이척도를 이용하여 (1) 고객철학(customer philosophy), (2) 통합마케팅조직 (integrated marketing organization), (3) 적절한 마케팅 정보(adequate marketing information), (4) 전략적 지향성(strategic orientation), (5) 운영상의 효율성(operational efficiency)에 관한, 즉, 문화와 전략차원의, 마케팅 수준을 종합적으로 측정하고자 시도하였다. 물론 이러한 시도는 마케팅역량에 관한 전반적인 면을 측정하고자 한 초기의 시도라는 점에서 상당한 의미를 찾아볼 수 있으나, 이 항목들이 마케팅역량 전반을 제대로 측정하고 있는가라는 점에 대해서는 의문이 든다. 예를 들어 시장지향적 문화의 경우 일부 철학적인 항목만을 측정하고 있고, 전략의 경우에도 일부 전략적 지향성이나 마케팅조직의 공식성을 측정하고 있으나, 이에 의하여 기업 마케팅전략의 수준을 제대로 측정하는 것은 무리가 있는 것으로 판단된다.

두 번쩨로 마케팅 효과성은 문화 차원, 전략 차원의 마케팅 요소들을 구분하고 있지 않음에 따라 이들의 관계는 상정하고 있지 않다. 따라서 마케팅 효과성에 의하여 기업 성과를 예측할 수는 있지만, 각 차원별 마케팅 요소간 관계 규명을 통한 마케팅 할동의 개선방향을 도출하기는 어렵다. 이에 본 연구는 마케팅역량의 구성요소간 관계의 설정과 측정을 통하여 마케팅역량과 성과와의 관계를 체계적으로 밝히고자 한다.

한편 마케팅역량의 계충적 모델에 관한 연구(Hooley et al., 1999)는 마케텅을 문화, 전략, 전술의 차원으로 이해할 것을 제안한 Webster (1993, 1995)의 틀을 기반으로 하여, 이 세 가지 차원별로 마케팅역량을 측정하고 성과와의 관계률 규명하였다. 따라서 이 연구는 마케팅 효과성에 관한 연구들과는 달리 마케팅역량을 구성하는 차원별 요소를 명시적으로 정의하고 각 요소의 역할을 고찰한 연구의 효시라 할 수 있다. Hooley 둥 (1999)은 자원준거적 관점에 기반하여 마케팅역량 차원 중 가장 상위요소인 문화로서의 마케팅은 경쟁자 입장에서 볼 때 복잡하고 인과관계가 모호한 자원활용에 해당하므로 하위 요소들인 전략이나 전술차원의 마케팅요소에 의한 경쟁우위보다 더 큰 경쟁우위요소로서의 잠재력을 갖는다고 주장하였다. 따라서 시장지향적인 문화는 마케팅전략이나 전술보다 성과와 더 밀접하게 연관될 것이라는 가설을 제시하였다. 따라서 이들의 연구는 마케텅 
역량의 제 차원을 통합적인 관점에서 이해 측정하고 성과와의 관계를 규명했다는 점에서 상당한 의의가 인정된다.

그러나 Hooley 등(1999)의 연구 또한 몇 가지 한계를 내포하고 있다. 먼저 이들의 연구에서 사용된 측정척도들은 개념타당성 측면에서 문제를 가지고 있다. 우선 시장지향성의 경우, Narver와 Slater (1990)의 척도를 사용함으로써 시장지향성을 문화로 정의하면서 측정은 행동적 요소에 국한하는 한계를 극복하지 못하였다(Homburg \& Pflesser, 2000 ). 행동적 요소로 측정한 시장지향적 문화는 마케팅전략과 개념적으로 구분되기 어렵기 때문에 시장지향적 문화의 정의를 반영하는 측정치를 마련하기 위해서는 시장지향적 가치관, 규범, 인위적인 장치를 고려하는 것이 바람직하다(Harris, 1998). 또 다른 문제점은 마케텅전략수준에 대한 측정에서 발견된다. Hooley 둥(1999)은 마케팅전략수준을 제품, 서비스, 가격이라는 세 가지 차원의 상대적인 포지션 정도로 측정하였는데 이는 마케팅전략의 결과를 측정한 것이지 과정이나 내용에 대한 측정은 아니다. 전략으로서의 마케팅수준을 측정하려면 마케팅전략이 수립되고 실행되는데 필요한 요소들의 수준을 측정하든지(Menon et al., 1999), 해당 기업이 처한 상황과 그 기업이 선택한 전략유형간의 적합도를 측정하는 것이 더 바람직한 접근일 것이다(Miles \& Snow 1978; Morgan \& Strong 1998; Venkatraman, 1989). 한편 전술을 측정하기 위하여 Hooley 둥(1999)은 Day (1994)의 마케팅역량을 조작적 정의로 사용하였다. 그러나 전략 실행에 대한 측정은 이러한 역량 뿐만 아니라 조직구조 및 실행행동 차원의 요소들을 포합하는 것이 필요하다(Menon et al., 1999; Noble \& Mokwa, 1999).

나아가 Hooley 등(1999)의 연구를 발전시킬 수 개념화의 방향은 마케팅역량의 각 요소(문화, 전략, 전술)와 성과간의 관계만 아니라 마케팅역량올 구성하는 각 차원별 요소간의 관계를 고려함으로써 찾아볼 수 있다. 지금까지 마케팅역량의 각 요소가 성과에 미치는 상대적인 영향력은 규명되었지만, 이러한 영향의 과정은 고려되지 않았다. 그러나 전략에 관한 다른 선행연구들은 전략이 문화와 성과사이롤 매개하는 것을 시사하고 있다(Bigne et al., 2000; Morgan \& Strong, 1998; Ruekert, 1992). 따라서 본 연구는 개념적 정의에 충실한 척도를 사용하고, 마케팅역량 요소간의 관계를 추가적으로 살펴봄으로써 마케팅역량 요소와 성과간의 관계를 보다 충실하게 규명하고자 한다.

\subsection{2 시장지향적 문화, 마케팅전략과정과 성과}

시장지향적 문화가 바랍직한 기업성과를 담보하기 위해서는 어떤 식으로든 기업성과 달성에 적합한 시장지향적인 활동과 행위들이 기획 - 실행되어야 하며(Morgan \& Strong, 1998), 이롤 위한 프로세스는 전략수단을 통해 마련된다(Slater \& Narver, 1993, 1995). 즉 시장지향성을 시장(고객, 경쟁자, 기타 관계자)으로부터 정보를 힉득.전가하고 부서간 공조를 통해 대웅하는 활동을 촉진하는 문화라고 볼 때(Kohli \& Jaworski, 1990; Narver \& Slater, 1990), 전략은 이러한 문화의 바탕에서 힉득된 시장의 정보롤 분석하고, 학숩을 통해 최적의 경쟁전략대안을 도출하고, 이를 가장 효과적으로 실행에 옮기는 과정으로 볼 수 있다(Baker \& Sinkula, 1999; Hurley \& Hult, 1998; Menon et a1., 1999; Noble \& Mokwa, 1999; Sinkula, 1994; Sinkula, Baker, \& Noordewier, 1997; Slater \& Narver, 1995). 그러므로 전략 수립과 실행 과정은 시장지향적 문화가 사업성과에 긍정적으로 작용할 수 있도록 관리해주는 과정이다(Day, 1994; Slater and Narver, 1993). 따라서 아래와 같은

가설을 설정하여 검증하고자 한다. 
가설 3 : 시장지향적 문화는 마케팅전략과정을 통해 성과에 긍정적인 영향을 미칠 것이다.

\section{3. 연구방법}

\section{1 표본 추출과 자료 수집}

본 연구의 표본 프레임은 한 신용정보희사의 기업체 명단이었다. 수도권 지역에 소재한 기업들 중 업종과 기업규모의 분포를 고려한 판단추출을 활용하여 조사대상 기업을 선정하였다. 총 120 개의 기업체를 조사대상으로 선정하여 이 기업들에게 연구목적을 알리고 설문조사에 대한 협조를 구하는 서신을 발송하였다. 그 후, 서신의 접수여부와 설문조사에 웅할 의사를 확인하는 전화통화가 이루어졌다. 설문조사에 웅할 의사를 밝힌 기업체에 훈련된 조사원이 방문해서 면접조사를 실시하였다. 충 120 개 조사대상 기업 중 113 개의 기업이 조사에 웅했으며, 이 중 응답내용이 불성실한 3 개의 설문지를 제외한 110 개의 설문지가 최종 분석에 활용되었다.

\section{2 변수의 측정}

\section{2 .1 시장지향적 문화}

대부분의 시장지향성 척도들은 대표적인 척도인 Narver와 Slater (1990)의 척도나 Kohli와 Jaworski (1990)의 경우를 받아들인 행동적 관점의 척도이다(Homburg \& Pflesser, 2000). 본 연구는 문화에 대한 체계적인 개념적 고찰(Deshpande \& Webster, 1989; Schein, 1992; Trice \& Beyer. 1993)을 바탕으로 문화로서의 시장지향성을 새롭게 정의하고 측정한 Homburg와 Pflesser (2000)의 척도를 사용하여 시장지향적 문화를 측정하였다 ${ }^{2}$. (<부록 : 측정항목> 참조).

\section{2 .2 마케텅전략과정}

본 연구는 마케팅전략의 수립과 실행을 통합한 마케팅전략과정이란 개넘에 의거하여 마케팅전략과 전술에 대하여 측정하였다. 이론적 고찰과 연구가설 설정에서 논의하였듯이, 마케팅전략과정은 상황분석, 포괄성, 세분화 전략원칙(STP), 기능-부서간 통합, 의사소통, 합의도출 몰입도, 자원 몰입도, 실행역량 (4P 믹스 활용의 합리성), 통제 요소들로 구성되었다(Becker \& Homburg, 1999; Boyd \& Reuning-Elliott, 1998; Menon et al., 1996). 상황분석, 포괄성. 마케팅역량에 대한 강조, 기능-부서간 통합, 의사소통, 합의도출 몰입도, 자원 몰입도는 Menon 둥(1999)의 연구에서 사용된 척도를 이용하였으며, 전략원칙(STP), 실행역량(4P 믹스 활용의 합리성)은 Kotler (1977, 1997)와 Yoon과 Kim

2 시장지향적 행동에 관한 항목은 마케텅전략과정의 부분집합에 해당하며(Homburg \& Pflesser, 2000, ). 문화의 정의가 행동올 직접적으로 포함하지 않는다는 점을 고려하여(Deshpande \& IVebster, 1989; Hatch, 1993; Schein, 1992) 본 연구에서논 활용되지 않았다. 
(1999)의 척도를 이용하였고, 통제는 Becker와 Homburg (1999)의 척도를 사용하였다 (<부록 : 측정항목> 참조).

3.2 .3 성과 및 통제 변수

성과는 시장성과변수를 활용하여 측정하였다(Homburg \& Pflesser, 2000). 시장성과는 기업 마케팅 활동의 효과성으로 정의되며(Homburg \& Pflesser, 2000; Irving, 1995), 경쟁자와 비교한 고객만족도, 대(對) 고객가치, 고객유지, 고객유치, 매출성장률, 목표시장점유율 달성도로 구성되었다.

본 연구에서 설정한 관계는 다양한 외생변수들의 영향에 노출되어 있다. 따라서 본 연구에서 설정한 관계들이 이러한 외생변수의 영향을 배제한 후에도 성립되는지를 검증하기 위하여 시장지향적 문화와 마케팅전략의 주요 선행연구를 참고하여 환경격변성을 통제변수로 설정 · 측정하였다.

\section{4. 분석 및 결과}

\section{1 신뢰성 분석}

측정항목들의 내적 일관성에 기초하여 신뢰도를 측정하는 통계치인 크론바 알파 계수(Churchi11, 1979)를 이용하여 본 연구에서 측정한 항목들의 신뢰도를 검증한 결과, 본 연구의 개념들은 <표 $1>$ 과 같이 모두 a 값이 0.7 이상으로 기준 이상의 신뢰성을 가지고 있는 것으로 나타났다(Nunnally, 1970).

<표 1> 신뢰도 분석결과

\begin{tabular}{|c|c|c|}
\hline 측정개념 & $\begin{array}{c}\text { 축정항목 } \\
\text { 수 }\end{array}$ & $\mathrm{a}$ \\
\hline 가치관 & 17 & 0.91 \\
\hline 규범 & 17 & 0.94 \\
\hline 인위적 장치 & 14 & 0.85 \\
\hline 상황분석 & 5 & 0.90 \\
\hline 포괄성 & 3 & 0.88 \\
\hline 전략원칙 & 6 & 0.91 \\
\hline 기능-부서간 통합 & 3 & 0.89 \\
\hline
\end{tabular}

\begin{tabular}{|c|c|c|}
\hline 측정개념 & $\begin{array}{c}\text { 측정항목 } \\
\text { 수 }\end{array}$ & $\mathrm{a}$ \\
\hline 의사소통 & 2 & 0.84 \\
\hline 합의도출 & 2 & 0.84 \\
\hline 자원몰입 & 3 & 0.82 \\
\hline 실행요소 & 10 & 0.90 \\
\hline 통제 & 4 & 0.82 \\
\hline 환경격변성 & 4 & 0.79 \\
\hline 시장성과 & 6 & 0.89 \\
\hline
\end{tabular}

\section{2 타당성 분석}

본 연구가 사용한 측정척도에 대한 타당성은 내용타당성(content or face validity)과 개념타당성(construct validity)으로 나누어 검토하였다. 전문가(학자), 실무진과의 토론과 
선행연구내용을 감안할 때 본 연구에서 다루는 개념들올 측정하기 위하여 사용한 척도들은 내용타당성을 갖추고 있는 것으로 판단되었다. 개념타당성은 확증적 요인분석(confirmatory factor analysis)을 사용하여 검증하였다. 측정항목들이 측정하고자 하는 개념과 상관관계가 있으며 여타의 개념과는 상관관계가 존재하지 않는다는 가정을 검증하기 위한 확증적 요인분석을 통하여 측정도구의 수렴타당성과 판별타당성올 검증하였다(Bagozzi \& Yi, 1988; Gerbing \& Anderson, 1988). 확증적 요인분석결과, 시장지향적 문화와 마케팅전략 변수들의 모든 계수들이 유의하였으며 $(t>2.00)$ 표본의 수를 고려한 적합도 지수가 기준을 상회하고 있어(CFI > 0.9), 본 연구에서 활용한 측정 척도들이 적정 수준의 개념타당성을 확보하고 있음을 보여주었다(<그림 4>와 <그림 5> 참조). 또한 시장지향적 가치관, 시장지향적 규범, 시장지향적 인위장치의 판별타당성에 대한 추가적인 분석에서도 상관계수와 표준오차 $(\mathrm{SE})$ 가 각각 $\Phi_{12}=0.36 \quad(\mathrm{SE}=0.09), \quad \Phi_{23}=0.55 \quad(\mathrm{SE}=0.11), \quad \Phi_{13}=0.37$ $(\mathrm{SE}=0.09)$ 로 나타났다. 따라서 $\Phi$ 의 신뢰구간 $(\phi \pm 2 \mathrm{SE})$ 내에 1 이 포함되어 있지 않으므로 각 개념들간의 판별타당성을 확인할 수 있었다.

<그림 4> 확증적 요인분석결과 : 시장지향적 문화

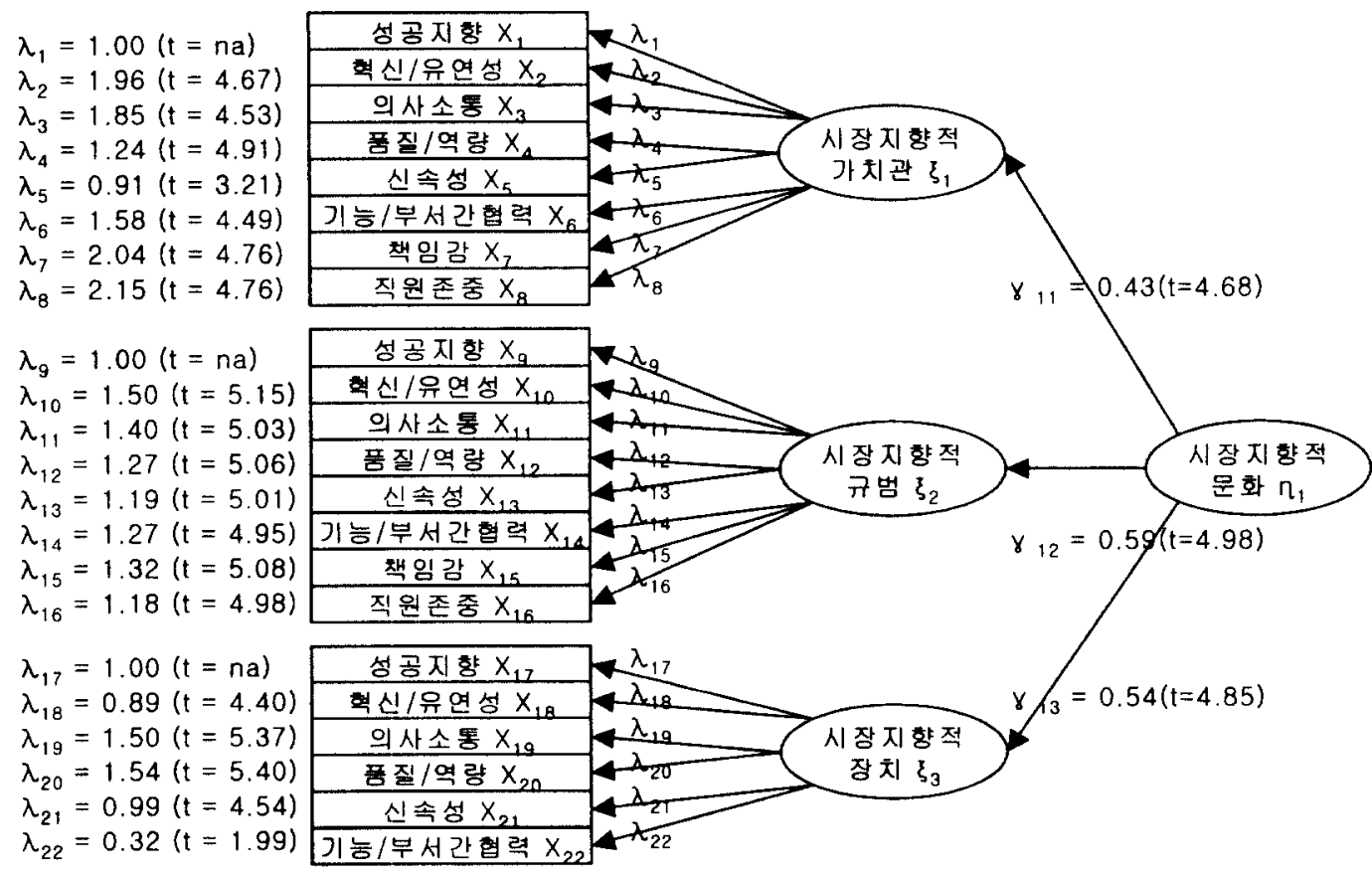

모델 적합 지수 : $\chi^{2}=325.46(\mathrm{~d} f=201, \mathrm{p}=0.00), \mathrm{GFI}=0.80, \mathrm{RMR}=0.088, \mathrm{CF}=0.91$ 


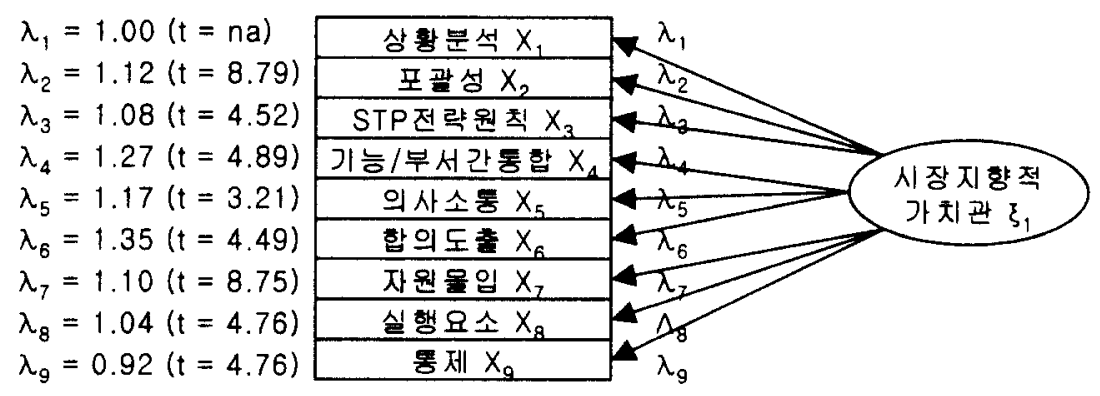

모델 적합 지수 : $\chi^{2}=53.39(\mathrm{df}=27, \mathrm{p}=0.00), \mathrm{GFI}=0.88, \mathrm{RMR}=0.040, \mathrm{CF} \mid=0.96$

\section{3 가설 분석결과}

가설검중은 아래와 같은 2 개의 희귀식에 대한 분석을 통해 이루어졌다. 회귀식(1)의 분석결과는 가설 $1,2,3$ 의 검증에 활용되었으며, 희귀식(2)의 분석결과는 가설 3 의 검증에 활용되었다. 회귀분석결과는 <표 2>와 같다.

(1) 시장성과 $=a+\beta_{1}$ 시장지향적 문화 $+\beta_{2}$ 마케팅전략과정 + $\beta_{3}$ 시장지향적 문화*환경격변성 $+\beta_{4}$ 마케팅전략과정*환경격변성 $+\varepsilon$

(2) 마케팅전략과정 $=a+\beta_{1}$ 시장지향적 문화 $+\varepsilon$

시장지향적 문화는 성과에 긍정적인 영향올 줄 것이라는 가설 1 을 검증하기 위해 회귀분석(1)을 실시한 결과, 시장지향적 문화는 시장성과에 유의한 영향을 주는 것으로 밝혀졌다. 베타계수가 양의 값이었으며, 유의하였다 $(\beta=.329, p<0.01)$. 따라서 시장지향적 문화가 성과에 긍정적인 영향을 미칠 것으로 예측한 가설 1은 지지되었다.

마케팅전략과정의 수준과 성과간의 긍정적인 관계를 상정한 가설 2 를 검중하기 위해 회거분석(1)을 실시하였다. 희귀분석 결과 마케팅전략과정의 베타계수는 양의 값이었으며, 유의하였다 $(\beta=.458, p<0.01)$. 따라서 마케팅전략과정이 성과에 긍정적인 영향을 미칠 것으로 예측한 가설 2 가 지지되었다.

시장지향적 문화가 마케텅전략과정을 통해 성과에 간접적인 영향올 미칠 것으로 예측한 가설 3을 검중하기 위해 경로분석을 실시하였다(Bollen, 1989; Moorman et al., 1996). 경로분석은 회귀식(1)과 회거식(2)의 베타계수를 활용하여 수행하였다. 가설 3 에서 예측하고 있는 시장지향적 문화의 마케팅전략과정올 통한 성과에의 간접적인 영향은 마케팅전략과정에 대한 시장지향적 문화의 베타계수(0.804)와 시장성과에 대한 마케팅전략과정의 베타계수(0.458)를 곱함으로써 도출할 수 있다. 이와 같은 과정을 통해

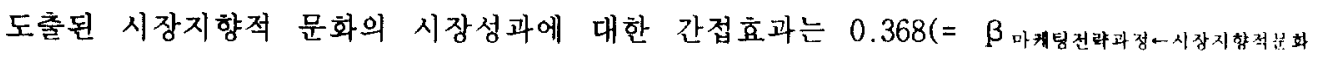
(0.804) X $\left.\beta_{\text {성과 마케링천략과정 }}(0.458)\right)$ 이었다. 따라서 시장지향적 문화가 마케팅전략과정을 통해 시장성과에 간접적인 영향을 미칠 것이라는 가설 3 도 지지되었다. 
회귀분석을 통해 시장지향적 문화가 마케팅전략과정에 유의한 영향을 미치는 것이 확인되었으며, 이를 토대로 시장지향적 문화가 마케팅전략과정을 통해 성과에 미치는 간접적인 영향을 도출하였다. 그러나 이 결과만으로는 시장지향적 문화가 어떤 과정을 통하여 마케팅전략과정수준에 영향을 미치는지를 규명하기 어렵다. 이에 따라 시장지향적 문화와 마케팅전략과정의 제 요소간의 관계를 분석하였다. 이를 위해 시장지향적 가치관, 규범, 인위적인 장치를 독립변수로, 마케팅전략과정의 제 요소들을 종속변수로 한 일련의 다중회귀분석을 실시하였다. 회귀분석 결과, 시장지향적 문화요소들은 마케팅전략과정의 구성요소들에 대체로 유의한 긍정적 영향을 주는 것으로 나타났다. 다만 시장지향적 규범은 마케팅전략과정의 모든 요소에, 인위적 장치는 포괄성과 통제를 제외한 모든 요소에 유의한 영향을 갖는 반면, 시장지향적 가치관은 합의도출과 $4 \mathrm{P}$ 믹스 실행에만 유의한 영향을 주는 것으로 밝혀졌다. 이러한 결과가 나타난 이유로는 가치관이란 성과를 향한 조직의 전반적인 행동양태에 영향을 주는 추상적인 개념인 반면 마케팅전략과정은 마케팅전략의 수립과 실행이라는 구체적인 개념이라는 개념의 수준 차이를 생각할 수 있으며 이에 따라 그 관계가 약하게 나타넜으리라 추정된다. 추가적으로 분석한 결과 마케팅전략과정에 대한 가치관의 영향은 규범에 반영되어 나타났을 가능성이 높다 $\left(\beta_{\text {규범-가치과 }}=.804 ; \beta\right.$ 인위젹인 장치 $\leftarrow$ 가치관 $=.218$ ).

마지막으로 환경격변성이라는 통제변수의 역할을 파악하기 위하여 시장성과에 대한 시장지향적 문화, 마케팅전략과정과 환경격변성의 상호작용효과를 분석하였다. 분석 결과, 환경격변성이 높아질수록 성과에 대한 시장지향적 문화의 영향력은 감소하는 반면( $\beta=-$ $.240, \mathrm{p}<0.1)$, 성과에 대한 마케팅전략과정의 영향력은 증가하는 것으로 $(\beta=.268$, $\mathrm{p}<0.05)$ 나타났다. 이러한 분석결과는 성과에 대한 시장지향성의 영향이 환경격변성이 높아질수록 약화되며(Slater \& Narver, 1994), 성과에 대한 마케팅전략의 영향은 환경격변성이 높아질수록 강화된다는(Menon et al., 1996) 기존의 연구결과와 일치하고 있다.

<표 2> 희귀분석 결과

\begin{tabular}{|c|c|c|}
\hline \multirow{2}{*}{ 독립변수 } & \multicolumn{2}{|c|}{ 종속변수 } \\
\cline { 2 - 3 } & 마케팅전략과정 & 시장성과 \\
\hline 시장지향적 문화 & $0.804^{* * *}$ & $0.329^{* *}$ \\
\hline 마케팅전략과정 & - & $0.458^{* *}$ \\
\hline 시장지향적 문화*환경격변성 & - & $-0.240^{*}$ \\
\hline 마케팅전략과정*환경격변성 & - & $0.268^{* *}$ \\
\hline $\mathrm{r}^{2}$ & 0.647 & 0.590 \\
\hline F값 & 188.95 & 36.84 \\
\hline Significance of $\mathrm{F}$ & 0.000 & 0.000 \\
\hline
\end{tabular}

$* p<0.1, * * p<0.05, * * * p<0.01$. 


\section{5. 결론 및 토의}

\section{1 연구결과의 의의}

본 연구결과롤 시장지향적 문화(Homburg \& Pflesser, 2000)와 마케팅전략과정(Menon et al., 1999)에 관한 대표적인 연구들과 비교하였을 때, 본 연구의 모형은 설명력과 베타계수 측면에서 향상된 모습을 보여주고 있다. 먼저 Homburg와 Pflesser (2000)는 시장지향적 문화를 구성요소들간의 계충적인 구조로 정의하고 가장 하위요소인 시장지향적 행동만이 성과에 영향을 준다고 본 반면, 본 연구는 Hatch (1993)에 기반하여 시장지향적 문화를 구성요소들간의 역동적인 상호작용으로 정의하고, 전체 요소들이 통합적인 개념으로서 성과에 영향을 미친다고 개념화하였다. 본 연구의 모델과 Homburg와 Pflesser (2000)의 모델을 비교하기 위하여 Homburg와 Pflesser(2000)의 모델을 설정하여 본 연구가 수집한 자료를 회귀분석하였다. 그 결과, 시장지향적 문화의 구성요소들은 계충적인 구조로도 해석이 가능하며, 시장지향적 행동은 성과에 유의한 영향올 미치는 것으로 밝혀졌다. 그러나 Homburg와 Pflesser (2000)에 의해 설정한 회귀분석에서 시장지향적 문화는 성과의 $27.1 \%$ 만을 설명한 반면, 본 연구의 모델은 $48.7 \%$ 를 설명하였다.

또한 본 연구는 마케팅전략과정의 구성요소에 대해 Menon 등(1999)의 측정 문제를 지적하고 이에 대한 개선을 시도하였다. 이들은 마케팅전략과정을 기업전략(corporate strategy)과정요소를 중심으로 개념화하고, 마케팅전략의 특성 반영을 위해 13가지의 마케팅역량에 대한 측정을 포함시켰다. 그러나 이들이 사용한 마케팅역량 측정항목들은 전략적 일관성, 마케팅자원의 효율적 활용 둥의 관점에서 볼 때 기업의 마케팅전략과정 수준을 측정하기에는 내용타당성이 부족한 것으로 판단하였다. 이에 본 연구는 Menon 둥의 마케팅역량 대신 마케팅전략원칙으로서의 STP, 마케팅실행요소로서의 $4 \mathrm{P}$ 믹스의 활용 효율성, 통제활동올 포함시켜 마케팅전략과정(MSM)을 개넘화하고 측정하였다. 따라서 본 연구의 모델과 Menon 등(1999)의 모델 비교는 마케팅전략과정요소의 개념적 발전방향을 모색하는 측면에서 의미가 있다. 분석 결과, Menon 둥(1999)의 연구모델 역시 유의하였으나,

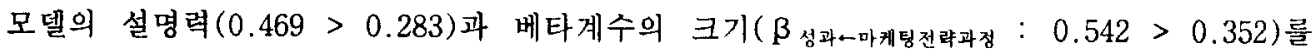
감안할 때 본 모델이 설정한 마케팅전략과정의 개념화가 의미 있다고 생각된다.

이러한 통계적인 결과의 특성이외에도 본 연구는 그 동안 개별적으로 수행된 연구 주제들을 통합하여 고찰한 의의가 있다. 즉 시장지향적 문화와 마케팅전략과정을 통합하여 마케팅역량에 대한 구조를 확인하고, 성과에 대한 영향의 과정을 밝혔다는 점에서 본 연구의 의의를 찾을 수 있다. 본 연구는 시장지향적 문화와 마케팅전략을 기업의 마케팅역량을 구성하는 차원으로 제기하였다. 나아가 문헌 고찰에 기반하여 시장지향적 문화가 마케텅전략과정올 동인(動因)하는 관계를 제시하였다. 즉 마케팅전략은 시장지향적 문화가 구체적인 마케팅 실행활동으로 연계됨에 있어 실행의 구심점과 방향을 제시해주는 역할을 수행한다는 점을 입중하였으며, 특히, 환경격변성이 높아질수록 마케팅전략과정의 역할 비중이 중가한다는 점을 밝혔다. 결국 본 연구의 주된 주장은 시장지향적 문화와 마케팅전략과정 모두가 담보되지 않고서는 우수한 성과의 달성을 기대하기 어렵다는 것이다. 즉 기업이 마케팅역량의 제고를 통해 시장성과를 제고시키기 위해서 시장지향적 문화의 
토대 위에서 충실한 마케팅전략과정을 이행해야 한다고 결론지을 수 있다.

\section{2. 연구의 한계점 및 향후 연구방향}

본 연구는 조직문화의 관점에서 시장지향성올 다시 정의하고, 이러한 시장지향성과 성과와의 관계에 있어서 마케팅전략과정의 매개변수 역할을 규명하였다. 대체로 이러한 관계는 입증되었으나, 본 연구 또한 몇 가지 한계점들을 가지고 있다.

우선 조사방법상의 한계롤 들 수 있다. 본 연구와 같은 연구주제들은 동일 조사단위에서 복수의 웅답자로부터 웅답을 구하는 것이 바람직하다(Kohli et al., 1993). 그러나 본 연구에서 복수 웅답자의 활용은 매우 제한적이었다. 분석에 활용된 총 110 개의 표본 중 복수 웅답자를 활용한 경우는 20개에 지나지 않았다. 물론 이 표본에 해당하는 20 개 조사단위와 나머지 조사단위로부터 표집한 응답결과간의 동질성은 확보되었지만, 전체 표본을 대상으로 복수 응답을 확보하지 못한 것은 본 연구의 한계점이다.

두 번째로 시장지향적 문화구성요소의 정의에 관한 한계를 생각할 수 있다. 조사 결과 시장지향적 문화의 일부 측정항목들의 경우 상대적으로 타당도가 부족한 부분이 있었으며, 구성요소간의 상관관계가 다소 높은 부분이 관찰되었다. 이러한 관찰은 외국의 선행연구에서 활용하고 있는 시장지향적 문화의 정의를 국내 기업들에 적용하는 과정에서 무리가 있는 부분이 있음을 시사한다. 향후 연구에서는 국내 환경에 더 적합한 시장지향적 문화를 개념화하는 것이 바람직할 것이다.

세 번쪠로 본 연구는 횡단적 조사결과에 기초한 한계를 가지고 있다. 종단적인 자료에 의해 본 연구에서 규명된 관계를 확인하는 향후 노력이 필요하다.

이러한 한계점들을 극복하려는 향후 연구 노력은 계속 되어야 하겠지만 또 하나의 중요한 향후 연구방향은 성과에 관한 부분이다. 보다 장기적인 마케팅활동의 성과로 등장한 시장기반자산(market-based asset; Srivastava et al., 1998; 이학식-김영, 2000), 브랜드자산(Keller, 1998), 또는 고객자산(Blattberg et al., 2001; Gupta et al., 2002; Rust et al., 2001)을 성과변수로 하여 본 연구에서 다룬 시장지향적 문화와 마케텅전략과정의 영향을 살겨보는 연구노력은 매우 가치가 높을 것이다. 


\section{<참고문헌>}

김훈·채서일(1996), “한국기업과 국내진출 외국계기업의 마케팅전략 비교연구,"

마케팅연구, 제11권, 제2호, 45-65.

노전표(1998), "우리나라 100대 제조기업의 시장지향성에 관한 연구," 전략겅영연구, 제

1권 제 1호, 75-99.

박세훈(1994), "광고비 변동에 따른 판매 반웅에 관한 연구," 경영화연구, 제23권, 제3호, 251-279.

이학식·김영 (2000), “재무성과와 기업가치에 대한 마케팅자산의 영향," 마케팅연구, 제15권, 제4호, 45-79.

이용기·유동근·이학식(1996), "시장지향성 : 선행요인, 매개요인, 그리고 성과간의

구조적 관계," 마케팅연구, 제11권, 제1호, 75-91.

장세진(2002), 글로벌 시대의 경영전략, 박영사.

김재욱-전광호·이성근(2001), "시장지향성이 유통경로의 관계적 성과에 미치는 영향 : 유통업체 관점," 마케팅연구, 제 16권, 제2호, 93-113.

전인수 · 김주환(2001), “선발이점 극복을 위한 후발제품의 마케팅전략에 관한 연구,"

경영하연구, 제 30 권, 제3호, 745-762.

Appia-Adu, K. (1999), "Marketing Effectiveness and Customer Retention in the Service

Sector," Service Industries Journal, 19 (3), 26-41.

Ayers, D., R. Dahlstron, and S. J. Skinner (1997), "An Exploratory Investigat ion of

Organizational Antecedents to New Product Success," Journal of Marketing Research, 34 (February), 107-16.

Bagozzi, R. P. and Youjae Yi (1988), "On the Evaluation of Structural Equation

Models," Journal of the Academy of Marketing Science, 16 (Spring), 74-94.

Barney, J. (1997), Gaining and Sustaining Competitive Advantage, Reading, MA:

Addi son-Wesley.

Baker, H. E. and J. M. Sinkula (1999), "The Synergistic Effect of Market Orientation and Learning Orientation on Organizational Performance," Journal of the Academy of Marketing Science, 27 (4), 411-427.

Bartol, K. M. and D. C. Martin (1998), Management, Boston: Irwin/McGraw-Hill.

Becker, J. and C. Homburg (1999), "Market-Oriented Management: A Systems-Based Perspective," Journal of Market Focused Management, 4, 17-41.

Bharadwaj, S. G., P. R. Varadarajan, and J. Fahy (1993), "Sustainable Competitive Advantage in Service Industries: A Conceptual Model and Research Propositions," Journal of Marketing, 57 (October), 83-99.

Bigne, E., N. Vila-Lopez, and I. Kuster-Boluda (2000), "Competitive Positioning and Market Orientation: Two Interrelated Constructs," European Journal of Innovation Management, 3 (4), 190-198.

Blattberg, R. C., G. Getz, and J. S. Thomas (2001), Customer Equity: Building and Managing Relationships as Valuable Assets, The Harvard Business School Press.

Bollen, K. A. (1989), Structural Equations with Latent Variables, John Wiley \& Sons. 
Bonoma, T. V. (1984), "Making Your Marketing Strategies Work," Harvard Business Review, 62 (March/April), 69-76.

(1985), The Marketing Edge: Making Strategies Hork, New York: The Free Press.

---- and V. L. Crittenden (1988), "Managing Marketing Implementation," Sloan Management Journal, 5 (3), 241-264.

Bourgeois, L. J. III and K. M. Eisenhardt (1988), "Strategic Decision Processes in

High Velocity Environments: Four Cases in Micro- Computer Industry," Management Science, 34 (July), 816-835.

Boyd, B. K. and E. Reuning-Elliott (1998), "A Measurement Model of Strategic Planning," Strategic Management Journal, 19, 181-192.

Capon. N., J. U. Farley, and J. M. Hulbert (1994), "Strategic Planning and Financial

Performance: More Evidence," Journal of Management Studies, 31 (January), 105-110.

Cespedes. F. V. (1991), Organizing and Implementing the Marketing Effort, Reading,

MA: Addison-Hesley.

------ and N. F. Piercy (1996), "Implementing Marketing Strategy," Journal of Marketing Management, 12 (1-3), 135-160.

Chaffee, E. (1985). "Three Models of Strategy," Academy of Management Review, 10 , 89-98.

Day, G. S. (1983), "Gaining Insights Through Strategy Analysis," Journal of Business Strategy, 4 (Summer), 51-58.

-...-- (1994), "The Capabilities of Market-Driven Organizations," Journal of Marketing, 58, 31-44.

Deshpande, R. and F. E. Hebster (1989), "Corporate Culture and Marketing: Defining the Research Agenda," Journal of Marketing, 53 (1), 3-15.

and J. U. Farley (1998), "Measuring Market Orientation: Generalization and Synthesis," Journal of Market Focused Management, 2 (1), 213-232.

Dwyer, R. F. and S. Oh (1988), "A Transaction Cost Perspective on Vertical Contractual Structure and Inter-Channel Competitive Strategies," Journal of Marketing, 52 (January), 11-27.

Eisenhardt, K.M. (1989), "Making Fast Decisions in High Velocity Environments," Academy of Management Journal, 32 (September), 543-576.

Fredrickson, J. W. (1983), "Strategic Process Research: Questions and Recommendations," Academy of Management Review, 8 (October), 565-75.

Gerbing. D. W. and J. C. Anderson (1988), "An Updated Paradigm for Scale Development Incorporating Unidimensionality and Its Assessment," Journal of Marketing Research, 25 (May), 186-192.

Grant, R. (1995), Contemporary Strategy Analysis, Cambridge, MA: Blackwell Publishers. Gummesson, E. (1998), "Implementing Requires a Relationship Marketing Paradigm," Journal of the Academy of Marketing Science, 26 (3), 242-249.

Gupta, S., D. Lehmann, and J. A. Stuart (2002), "Valuing Customers," Horking Paper, Columbia Business School. 
Hamel, G. and C. K. Prahalad (1994), Competing for the Future, Harvard Business School Press, Boston, MA.

Han J. K., N. Kim, and R. K. Srivastava(1998), "Market Orientation and Organizational Performance: Is Innovation a Missing Link?" Journal of Marketing, 62 (0ctober), 30-45.

Hart, S. L. and C. Banbury (1994), "How Strategy-Making Process Can Make a Difference," Strategic Management Journal, 15 (May), 251-70.

Harris, L. C. (1998), "Cultural Domination: the Key to Market-Oriented Culture?" European Journal of Innovation Management, 32 (3/4), 354-373.

Hatch, M. H. (1993), "The Dynamics of Organizational Culture," Academy of Management Review, 18 (4), 657-93.

Homburg, C. and C. Pflesser (2000), "A Multiple-Layer of Market-Oriented Organizational Culture: Measurement Issues and Performance Outcomes," Journal of Marketing Research, 37 (November), 449-462.

Hooley, G. J., J. Fahy, T. Cox, J. Beracs, K. Fonfara, and B. Snoj (1999), "Marketing Capabilities and Firm Performance: Hierarchical Model," Journal of Market Focused Management, 4, 259-278.

Hurley, R. F. and T. M. Hult (1998), "Innovation, Market Orientation and Organizational Learning: An Integration and Empirical Investigation," Journal of Marketing, 62 (4), 42-54.

Iaquinto, A. L. and J. W. Fredrickson (1997), “Top Management Team Agreement About the Strategic Decision Process: A Test of Some of Its Determinants and Consequences," Strategic Management Journal, 18 (January/February), 63-76.

Irving, E. (1995), "Marketing Quality Practices," Unpublished Dissertation, The Business School, University of North Carolina, Chapel Hill.

Kohli, A. K. and B. J. Jaworski (1990), "Market Orientation: The Construct, Research Propositions and Managerial Implications," Journal of Marketing, 54 (3), 1-18.

----- -- and A. Kumar (1993), "MARKOR: A Measure of Market Orientation," Journal of Marketing Research, 30 (November), 467-77.

Kotler, P. (1977), "From Sales Obsession to Marketing Effectiveness," Harvard Business Review, 55 (November-December), 67-75.

(1997), Marketing Management: Analysis, Planning, Implementation, and Control, Prentice Hall, Englewood Cliffs, N.J.

Lafferty, B. A. and G. T. M. Hult (2001), "A Synthes is of Contemporary Market Orientation Perspectives," European Journal of Marketing, 35 (1/2), 92-109.

McKee, D. 0., P. R. Varadarajan, and J. Vassar (1990), "A Taxonomy of Marketing Planning Styles," Journal of the Academy of Marketing Science, 18 (Spring), 131142.

Menon, A., S. G. Bharadwaj, P. T. Adidam, and S. W. Edison (1999), "Antecedents and Consequences of Marketing Strategy Making: A Model and a Test," Journal of Marketing, 63 (Apri1), 18-40. 
Miles, R. E. and C. C. Snow (1978), Organizational Strategy and Process Structure, McGraw-Hill, New York: N. Y.

Miller, D. (1987), "The Structural and Environmental Correlates of Business Strategy," Strategic Management Journal, 8 (January-February), 55-76.

Minzberg, H. and J. B. Quinn (1996), The Strategy Process: Concepts, Contexts, Cases, $3^{\text {rd }}$ ed., Prent ice-Hall.

Monroe, K. and R. Krishnan (1985), "The Effect of Price on Subjective Product Evaluations," in The Perceived Quality, eds., J. Jacoby and J. Olson, Lexington, MA: Lexington Books, 209-232.

Moorman, C. and A. S. Miner (1998), "The Convergence of Planning and Execution: Improvisation in New Product Development," Journal of Marketing, 62 (July), 1-20.

----- and R. T. Rust (1999), "The Role of Marketing," Journal of Marketing, 63 (Special Issue), 180-197.

------, G. Zaltman, and R. Deshpande, "Relationships Between Providers and Users of Market Research: The Dynamics of Trust Within and Between Organizations," Journal of Marketing Research, 29 (August), 314-328.

Morgan, R. E., and C. A. Strong (1998), "Market Orientation and Dimensions of Strategic Orientation," European Journal of Marketing, 32 (11/12), 1051-1073.

Morgan, R. M. and S. D. Hunt (1994), "The Commitment-Trust Theory of Relationship Market ing," Journal of Marketing, 58 (3), 20-38.

Narver, J. C. and S. F. Slater (1990), "The Effect of Market Orientation on Business Profitability," Journal of Marketing, 54 (October), 20-35.

------- and ----- (1998), "Additional Thoughts on the Measurement of Market Orientation: A Comment on Deshpande and Farley," Journal of Market Focused Management, 2, 233-236.

Noble, C. H. and M. P. Mokwa (1999), "Implementing Market ing Strategies: Developing and Testing a Managerial Theory," Journal of Marketing, 63 (October), 57-73.

Norburn, D., S. Birley, M. Dunn, and A. Payne (1990), "A Four Nation Study of the Relat ionship between Market ing Effectiveness, Corporate Culture, Corporate Values, and Market Orientations," Journal of International Business Studies, 21 (3), 45168.

Nunnally, J. C. (1970), Introduction to Psychological Measurement, McGraw-Hill, New York: N. Y.

Nutt, P. C. (1993), "The Formulation Processes and Tactics Used in Organizational Decision Making," Organization Science, 4 (May), 226-251.

Olson, E. R., 0. C. Walker, and R.W. Ruekert (1995), "Organizing for Effective New Product Development: The Moderating Role of Product Innovativeness," Journal of Marketing, 59 (January), 48-62.

Piercy, N. F. (1998), "Marketing Implementation: The Implications of Marketing Paradigm Weakness for the Strategy Execution Process," Journal of the Academy of Marketing Science, 26 (3), 222-236. 
Ramanujan, V., N. Venkatraman, and J.C. Camillus (1986), "Mult i-Object ive Assessment of Effectiveness of Strategic Planning: A Discriminant Analysis Approach," Academy of Management Journal, 29 (June), 347-372.

Ruekert, R. W. (1992), "Developing A Market Orientation: An Organization Strategy Perspective," International Journal of Research in Marketing, 9, 225-245.

Rust, R. T., V. A. Zeithaml, and K. N. Lemon (2001), Driving Customer Equity: How Customer Lifetime Value Is Reshaping Corporate Strategy, The Free Press.

Schein, E. H. (1992), Organizational Culture and Leadership, 2nd ed., San Francisco, Jossey-Bass Publishers.

Schweiger, D. M., W.R. Sandberg, and J. W. Ragan (1986), "Group Approaches for Improving Strategic Decision Making: A Comparative Analysis of Dialectical Inquiry, Devil's Advocacy, And Consensus Approaches to Strategic Decision Making," Academy of Management Journal, 29 (March), 51-71.

Sin, L. Y. M. and A. C. B. Tse (2000), "How Does Marketing Effectiveness Mediate the Effect of Organizational Culture on Business Performance? The Case of Service firms," Journal of Service Marketing, 14 (4), 295-309.

Sinkula, J. M. (1994), "Market Information Processing and Organizational Learning," Journal of Marketing, 58 (January), 35-45.

- W. E. Baker, and T. Noordewier (1997), "A Framework for Market-Based Organizational Learning: Linking Values, Knowledge and Behavior," Journal of the Academy of Marketing Science, 25 (4), 305-318.

Slater, S. F. and J. C. Narver (1993), "Product-Market Strategy and Performance: An Analysis of the Miles and Snow Strategy Types," European Journal of Marketing, 27 (10), 33-51.

- $----(1994)$, "Does Competitive Environment Moderate the Market Orientation-Performance Relationship?" Journal of Marketing, 58 (January), 46-55.

---- (1995), "Market Orientation and the Learning Organization," Journal of Marketing, 59 (July), 63-74.

------ (1996), "Competitive Strategy in the Market Focused Business," Journal of Market Focused Management, 1, 159-174.

Speed, R. (1993), "Maximizing the Potential of Strategic Typologies for Marketing Strategy Research," Journal of Strategic Marketing, 1, 171-188.

Srivastava, R., T. A. Shervani, and L. Fahey (1998), "Market-Based Assets and Shareholder Value: A Framework for Analysis," Journal of Marketing, 62 (January), 2-18.

Trice, H. M., and J. M. Beyer (1993), The Cultures of Work Organizations, Englewood Cliffs, NJ: Prentice Hall.

Venkatraman, N. (1989), "The Concept of Fit in Strategy Research: Toward Verbal and Statist ical Correspondence," Academy of Management Review, 14 (July), 423-444.

Webster, C. (1993), "Refinement of the Marketing Culture Scale and the Relationship between Marketing Culture and Profitability of a Service Firm," Journal of 
Business Research, 26 (February), 111-131.

(1995), "Marketing Culture and Marketing Effectiveness in Service firms," Journal of Service Marketing, 9 (2), 6-21.

Webster, F.E. (1988), "The Rediscovery of the Marketing Concept," Business Horizons, 31 (May-June), 29-39.

-_-.--- (1994), Market-Driven Management, New York: John Wi ley and Sons.

Wernerfelt, B. (1984), "From Critical Resources to Corporate Strategy," Strategic Management Journal, 5 (2), 171-180.

Wooldridge, B. and S. W. Floyd (1989), "Strategic Process Effects on Consensus,"

Strategic Management Journal, 14 (September), 451-78.

Yoon, S. and J. Kim (1999), "The New Approach to Assessing the Marketing Effectiveness of Korean Firms," Asia Pacific Journal of Management, 16 (2), 193212.

Zeithaml, V. A., A. Parasuraman, and L. L. Berry (1990), Delivering Quality Service: Balancing Customer Perceptions and Expectations, New York: The Free Press.

-.-1988), "Consumer Perceptions of Price, Quality, and Value: A Means-End Model and Synthesis of Evidence," Journal of Marketing, 52 (July), 2-22. 


\section{<부록 : 측정항목>}

\section{시장지향적 가치관(7점 동의척도)}

- 성공지향 :

- 우리 사업부는 직원들의 성과지향성(좋은 성과를 추구하는 성향)을 중시한다.

- 우리 사업부는 매우 성공 지향적이다.

- 혁신성 - 유연성 :

- 우리 사업부는 혁신성과 창의성을 특히 중시한다.

- 우리 사업부는 직원들의 유연성을 높이 평가한다.

- 의사소통 :

- 우리 사업부는 높은 수준의 부서간 정보교류를 추구한다.

- 우리 사업부는 정보 흐롬을 중요하게 생각한다.

- 우리 사업부는 적극적인 의사소통을 추구한다.

- 품질 역량 :

- 우리 사업부는 완벽한 업무처리률 중시한다.

- 우리 사업부는 높은 수준의 업무성과에 높은 가치를 부여한다.

- 신속성 :

- 우리 사업부는 모든 업무 프로세스에서 신속성을 추구한다.

- 우리 사업부에서는 모든 직원들이 업무 프로세스의 신속성을 추구한다.

- 기능 - 부서간 협력 :

- 우리 사업부는 기능 - 부서간 텀웍에 높은 가치를 부여한다.

- 우리 사업부는 각 기능들(예, 마케팅, 연구개발)간의 협력에 높은 가치를 부여한다.

- 책임감 :

- 우리 사업부는 모든 직원들이 CEO처럼 사고하고 행동하는 것을 중시한다.

- 우리 사업부는 직원들의 책임감을 매우 강조한다.

- 직원 존중 :

- 우리 사업부는 직원들에 대한 존중을 매우 강조한다.

- 우리 사업부는 높은 수준의 종업원 만족도를 추구한다.

\section{시장지향적 규범(7점 동의척도)}

- 구체적 성공 지향 :

- 우리 사업부는 주기적으로 마케팅 성과(예, 시장점유율, 고객만족)를 측정한다.

- 우리 사업부는 마케팅 성과를 일정한 목표 수준으로 관리하기 위해 노력한다.

- 구체적 혁신 - 유연성 :

- 우리 사업부는 마케텅 활동의 효과를 향상시키기 위해서 라면 표준업무내규(standard operation procedure)를 기꺼이 수정할 것이라고 믿는다.

- 우리 사업부는 부가가치를 창출하는 제품과 서비스를 지속적으로 발굴하고 개발할 수 있을 것이다.

- 우리 사업부는 새로운 아이다어(톡히 고객이 제시하는 경우)를 중시한다.

- 구체적 의사소통 : 
- 우리 사업부에는 시장과 관련된 문제점들을 기탄없이 거론할 수 있는 분위기가 형성되어 있다.

- 우리 사업부에서는 시장정보의 공유와 저장이 가능할 것이다.

- 구체적 품질 · 역량 :

- 우리 사업부는 고객으로부터 직접 품질올 평가 받거나, 혹은 최소한 고객의 관점에서 품질을 평가할 것 같다.

- 우리 사업부는 고객접점직원들에게 업무상 전문성은 물론 고객웅대 측면의 능력도 요구한다.

- 구체적 신속성 :

- 우리 사업부는 고객관련 업무처리 프로세스의 속도를 지속적으로 향상시킬 것으로 기대된다.

- 우리 사업부는 고객관련 업무처리 프로세스의 속도를 주기적으로 측정하고 후속조치를 시행할 것으로 기대된다.

- 우리 사업부는 시장변화에 대해 신속하게 대웅할 수 있을 것이다.

- 구체적 기능 - 부서간 협력 :

- 우리 사업부는 (예컨대, 여러 부서간 공조나 고객면접을 통해) 신제품(서비스) 개발에 고객의 의견이 반영되어야 한다는 분위기가 존재한다.

- 우리 사업부는 다양한 마케팅 활동과 관련된 의사결정의 조정 정도를 측정하고 후속조치를 시행한다.

- 구체적 책임감 :

- 우리 사업부는 현재 및 잠재 고객 욕구의 규명과 대응책 마련이 모든 직원의 소임이라고 여긴다.

- 우리 사업부는 모든 직원이 고객에 대해 높은 책임감을 가질 것을 요구한다.

- 구체적 직원 존중 :

- 우리 사업부는 각 직원들의 노력정도가 전체 성과에 영향을 줄 수 있다고 여긴다.

- 우리 사업부는 고객욕구 충족에 대해 직원들이 많은 관심을 기울일 것을 요구한다.

\section{시장지향적 인위적 장치들(7절 동의척도)}

- 모범사례 : 경영진(예, 설립자, 회장, 사장, 임원 둥)의 귀감이 될만한 고객지향적 행위가 자주 회자된다.

- 문제사례 :

- 낮은 시장지향성으로 인한 발생했던 사업부내의 문제점들이 자주 희자된다.

- 시장지향성을 저해하는 사업부내의 묵시적인 규칙과 관례들이 자주 회자된다.

- 제도 :

- 우리 사업부의 고객 접견실은 잘 꾸며져 있다.

- 우리 사업부의 회의실과 사무실은 의사소통이 용이하도록 설계되었다.

- 우리 사업부에는 비공식적인 정보교류에 적합한 희의/대화 공간(예, 카페테리아)이 마련되어 있다.

- 의식(儀式) :

- 우리 사업부에서는 귀감이 될 정도로 고객 지향적인 종업원에 대해 정기적으로 보상을 제공한다. 
- 우리 사업부는 정기적으로 중요 고객을 위한 이밴트를 갖는다.

- 우리 사업부는 제품이나 서비스의 제공을 위해 톡별 대고객 판매행사를 정기적으로 시행한다.

- 우리 사업부는 적어도 1년에 한번 이상은 고객을 만나서 앞으로 필요한 제품이나 서비스가 무엇인지 확인한다.

- 우리 사업부는 고객의 제품 선호 변화를 신속하게 파악하지 못한다.

- 제품과 서비스의 품질을 평가하기 위해 최소한 년 1회 이상 최종 소비자를 대상으로 조사를 실시한다.

- 우리는 소속 산업 내에서 발생하는 근본적인 변화(예컨대, 경쟁, 기술, 규제 등)를 신속하게 파악하지 못한다.

- 긍정적 언어습관(자주 사용하는 정도) :

- “이 문제를 고객의 관점에서 본다면..."

- “우리는 고객이 우리에게 기대하는 바를 제공할 수 있는가..."

- 부정적 언어숩관(자주 사용하는 정도) :

- "나는 고객이 무엇을 원하는지 매우 잘 안다..."

- "나는 경쟁사의 계힉에는 관심 없다. 우리는 이렇게 하면 되지 않나 ?"

- “이 상황에서 왜 변화가 펼요한가 ? 지금 상태면 충분하다고 본다"

\section{마케텅전략과정 (7점 동의척도)}

\section{우리 사업부는 마케팅전략의 수립을 위해}

\section{- 상황분석}

- 조직의 강점을 체계적으로 고려하고 있다.

- 조직의 약점을 체계적으로 고려하고 있다.

- 환경 전반(고객, 경쟁자, 규제당국, 사회/경제상황 둥)에 대해 체계적으로 정보를 수집하고 있다.

- 환경(고객, 경쟁자, 규제당국, 사희/경제상황 둥)의 기회요소를 체계적으로 고려하고 있다.

- 환경(고객, 경쟁자, 규제당국, 사회/경제상황 둥)이 주는 위협요소를 체계적으로 고려하고 있다.

- 포괄성 :

- 우리 사업부의 마케팅전략을 선택하기에 앞서 다양한 대안들올 고려해보았다.

- 선택된 마케텅전략은 유연하며 다양한 상황 변화(contingencies)를 반영하고 있다.

- 최종 전략의 선택에 앞서 각 대안들에 대한 적절한 분석이 수행되었다.

- 세분화 전략원칙 :

- 우리 사업부는 전체시장을 비슷한 욕구를 가진 세분시장의 관점에서 파악하고자 노력한다.

- 우리 사업부는 전체시장보다는 세분시장별로 접근하고자 노력한다.

- 우리 사업부는 목표시장의 선택을 위해 각 세분시장올 장기적인 성장과 이익의 관점에서 평가하고 있다.

- 우리 사업부는 목표시장의 선택을 위해 각 세분시장을 상대적인 경쟁우위의 관점에서 평가하고 있다. 
- 우리 사업부는 각 브랜드가 목표시장에서 차지하여야 할 독특한 지위를 찾아내기 위해 노력하고 있다.

- 우리 사업부는 목표시장에서 우리 브랜드가 경쟁사의 브랜드보다 유리한 지위률 확보하기 위해 부각시킬 필요가 있는 우리 브랜드의 특징을 찾아내고자 노력한다.

- 기능 - 부서간 통합

- 우리 사업부의 마케팅전략의 실행올 담당하고 있는 팀원들은 필요한 기술과 동기를 보유하고 있다.

- 우리 사업부의 마케텅전략의 실행 팀은 잘 조직되어 있다.

- 우리 사업부의 마케팅전략의 실행에 수반되는 활동들은 잘 조정되고 있다.

- 의사 소통 :

- 우리 사업부의 마케팅전략의 실행 주체들간에는 꾸준한 상호작용이 존재했다.

- 우리 사업부의 마케팅전략의 목적과 목표는 관련 당사자들에게 명확하게 의사소통 되었다.

- 합의 도출 :

- 우리 사업부의 마케팅전략의 실행 시 명확한 합의도출이 이루어졌다.

- 모든 관련 주체들이 이 전략에 심도 있게 참여했다.

- 자원 몰입 :

- 우리 사업부의 마케팅전략의 실행에 할당된 자원들의 종류는 적절했었다.

- 모든 사람들이 그들에게 주어진 시한을 맞추기 위해 최선을 다했다.

- 우리 사업부의 마케팅전략 실행에 적절한 자원이 할당되었다.

- 실행 요소 :

- 판매할 제품의 결정시 내부의 역학관계보다는 진정한 시장의 욕구에 입각한다.

- 가격 정책은 목표시장의 반웅에 대한 과학적인 분석에 기초하고 있다.

- 경쟁자의 중대한 가격 변화에 신속하게 대웅한다.

- 좋은 유통업체를 발견하면 신속하게 사업관계를 형성한다.

- 유통망 담당자는 고객의 관점에서 전문화되고 전략적인 유통망 정책을 실행하고 있다.

- 판매촉진 부서는 목표시장의 욕구에 기초한 판매촉진 활동을 전개하고 있다.

- 판매촉진 부서는 경쟁자의 촉진 활동에 신속하게 대응한다.

- 광고 담당부서는 목표시장의 욕구에 기초한 광고할동을 전개하고 있다.

- 광고 담당부서는 경쟁자의 광고활동에 신속하게 대응한다.

- 통제 :

- 주기적으로 전략목표와 실제성과를 비교한다.

- 전략목표와 실제성과에 대한 체계적인 비교가 이루어지고 있지 않다.

- 목표 달성도 평가 후 다양한 자료에 근거한(고객자료, 경쟁자자료, 관리회계 자료 둥) 원인 분석이 이루어지고 있다.

- 목표 달성도에 대한 원인 분석 후 즉시 수정조치가 취해진다.

성과

- 시장성과(7점 척도 : 매우 낮음 매우 높음) :

- 최근 3년간 귀사의 주요 경쟁사들에 대비한 귀사의 고객만족도는 ?

- 최근 3 년간 귀사의 주요 경쟁사들에 대비한 퀴사의 대고객 가치 제공 정도는 ? 
- 최근 3 년간 귀사의 주요 경쟁사들에 대비한 귀사의 기존 고객 유지는 ?

- 최근 3 년간 귀사의 주요 경쟁사들에 대비한 퀴사의 신규 고객 유치는 ?

- 최근 3 년간 귀사의 주요 경쟁사들에 대비한 귀사의 매출액 성장 정도는 ?

- 최근 3년간 귀사의 주요 경쟁사들에 대비한 귀사의 목표 시장 점유율 달성 정도는 ?

- 재무성과 : 최근 3 년간 귀 사업부의 평균 영업이익률(

\%) 